\title{
Docência em história no ensino médio, em turma regular, com a presença de aluno surdo
}

\author{
Heloisa Lima Perales? \\ Crislane Barbosa de Azevedo2
}

\section{RESUMO}

Este trabalho se constitui em uma reflexão sobre a prática pedagógica do professor de História de Ensino Médio, em turma regular, com a presença de aluno surdo, em uma escola pública de Natal-RN. Analisa como o professor planeja suas aulas, estrutura suas práticas e produz e/ou utiliza materiais didáticos com atenção aos alunos surdos. Foi realizada uma pesquisa bibliográfica e documental, bem como pesquisa de campo à luz da metodologia colaborativa, pautada na abordagem de pesquisa qualitativa, que contribuiu para a conscientização da professora sobre as necessidades específicas do aluno surdo e motivou mudanças atitudinais que se refletiram na sua prática pedagógica e, por consequência, na produção de recursos didáticos.

Palavras-chave: Fontes Históricas. Ensino de História. Formação de Professores.

\section{Teaching in history in senior high school in a regular school with the presence}

\section{of a deaf student}

\begin{abstract}
This work is a reflection on the pedagogical practice of the History teacher in High School in a regular classroom with the presence of deaf students in a public school in Natal-RN. It analyzes how the teacher plans his classes, structures his practices and produces and / or uses didactic materials with attention to deaf students. Literature and documentary research was done as well as field research in the light of the collaborative methodology based on the qualitative research approach. The research contributed to the teacher's awareness about the specific needs of the deaf student and motivated attitudinal changes that were reflected in their pedagogical practice and consequently in their production of didactic resources.
\end{abstract}

Keywords: Historical sources. Teaching History. Teacher training.

\footnotetext{
1 Mestrado em Educação. Docente da Universidade Federal do Rio Grande do Norte - Natal - RN - Brasil. Orcid iD: https://orcid.org/0000-0001-9318-7684. E-mail: heloisaperales@gmail.com

2 Doutorado em Educação. Docente da Universidade Federal do Rio Grande do Norte, Natal, Brasil. Orcid iD: https://orcid.org/0000-0003-3456-0025. E-mail: crislaneazevedo@yahoo.com.br
} 


\section{La enseñanza de historia en una escuela secundaria con presencia de estudiantes sordos. El caso de natal, rio grandel del norte, brasil}

\section{RESUMEN}

Este trabajo plantea una reflexión sobre la práctica pedagógica realizada en la asignatura de historia para estudiantes sordos en la Escuela Pública en Natal, Río Grande, Brasil. El objetivo principal es analizar cómo el maestro planifica las clases, estructura sus prácticas y utiliza los materiales de enseñanza con atención especial hacia los estudiantes sordos. El trabajo se sustenta en un enfoque cualitativo a través de la revisión teórica de investigaciones y documentos del tema. Esta investigación no sólo encontró que el profesor -en la Escuela Pública en Natalasumiera una mayor conciencia sobre las necesidades específicas del estudiante sordo, sino que contribuye a la reflexión y estudios de otros casos que son necesarios para motivar la práctica pedagógica y, por consiguiente, la producción de recursos didácticos en beneficio de la población estudiantil en situación de sordera y que requiere una atención e inclusión educativa especial.

Palabras clave: Fuentes históricas. La enseñanza de la historia. Formación de profesores.

\section{Introdução}

É imprescindível que as reais necessidades educacionais dos surdos sejam compreendidas, tendo em vista a melhoria dos processos de tomada de decisões em prol da garantia do direito a uma educação escolar de qualidade. Pensar sobre isso é refletir, também, sobre as práticas docentes que vêm sendo executadas nas escolas atuais, sobretudo em turmas de ensino regular nas quais estão presentes alunos surdos.

Nesse contexto, buscamos contribuir para a reflexão sobre as práticas pedagógicas do professor de História de Ensino Médio, em turma regular, com a presença do aluno surdo. Tomamos como campo de pesquisa uma escola pública na cidade de Natal-RN, buscando compreender o processo de planejamento de aulas de um professor de História nessa condição e como estrutura suas práticas, de modo a considerar as especificidades de alunos surdos. Este trabalho abre margem para que se entenda, por exemplo, como a presença de alunos surdos afeta a escolha das estratégias 
didático-pedagógicas do professor, inclusive a criação ou adaptação de material didático para atender às especificidades desse público.

O professor de História é formado para atuar em um universo escolar diversificado e complexo e nem sempre se sente preparado para isso. Apesar de o Decreto Federal 5.626 ter sido sancionado em 2005, o qual institui como obrigatória a disciplina de Libras (Língua Brasileira de Sinais) em todas as licenciaturas, essa formação pontual, circunscrita a um semestre letivo na graduação, nem sempre é considerada suficiente para que o futuro professor possa lidar com os desafios da formação do aluno surdo. Além disso, é preciso considerar a existência de grande parcela de professores formados em período anterior ao Decreto ou, ainda, grande parcela de professores que, mesmo formados após 2005, não tiveram a oportunidade de cursar a disciplina de Libras em decorrência da não regulamentação imediata em alguns cursos.

A escassez de pesquisas que abordassem a formação de alunos surdos em turmas de ouvintes, com foco em uma disciplina específica, chamou a nossa atenção, sobretudo no que diz respeito à História. Entre os trabalhos pesquisados, podemos citar o de Mesquita e Silva (2009), registro curto e pontual, posto que circunscrito a uma experiência de estágio supervisionado em História. Também destacamos a produção de Yokohama (2005), que levanta a questão: "Como ensinar História para surdos?", na qual evidencia a necessidade de desenvolvermos metodologias e procedimentos didáticos específicos para esse público. Neves (2009), por sua vez, relaciona a dificuldade do aluno surdo para aprender a História em decorrência da natureza complexa e específica dos conceitos da área. A comunicação falha em sala poderia acarretar limitações na aprendizagem, apesar de a perda auditiva em si não causar déficit cognitivo. Em contraste, Pereira (2017) defende a ideia de que é possivel trabalhar conceitos e conteúdos históricos com os alunos surdos, desde que o docente compreenda as especificidades da aprendizagem deles e use a Libras como primeira língua e o português escrito como segunda. 
Assim, o professor precisa, além do domínio da Libras, definir com clareza os objetivos que pretende alcançar com os alunos surdos, pensando nas estratégias que usará para que os conteúdos históricos sejam trabalhados para atendê-los. As obras supracitadas corroboram a importância do planejamento e, por extensão, da preparação do material pedagógico, pensando tanto nos alunos ouvintes como nas necessidades dos alunos surdos. Buscamos colaborar com a produção de conhecimento acerca da garantia do acesso à educação de qualidade para todos, contribuindo para a discussão sobre a efetivação de um adequado currículo para surdos.

A pesquisa de campo foi realizada em uma turma de $1^{a}$ série do Ensino Médio, da Escola Estadual Berilo Wanderley (EEBW), localizada no bairro Neópolis, Natal-RN. A estrutura física é excelente e possui entrada acessível com escada e rampa com boa largura, duas grandes áreas para estacionamento, ginásio de esportes coberto, depósitos para material esportivo e vestuários feminino e masculino. Possui sala de Artes, sala de Música e uma biblioteca muito espaçosa e organizada. Dispõe de treze salas de aula ao redor do pátio; uma sala de recursos multifuncionais; laboratório de informática com 21 computadores; laboratório de Física-QuímicaBiologia, em uma mesma sala, onde possui também 0 respectivo almoxarifado; laboratório de Matemática; laboratório de Línguas; TeleCentro Metrópole Digital/Multimídia; sala de livros didáticos e banheiros feminino e masculino para alunos.

A Escola ainda conta com uma sala de secretaria e sala de arquivo, bem como sala de material de expediente e sala de material de limpeza. Tem uma sala para a coordenação, com espaço reservado para reuniões; sala de professores, com banheiro exclusivo e armários individuais; além da sala de direção e vice-direção. A EEBW tem rádio própria. A cantina é ampla, com uma despensa para guardar alimentos. Toda a verificação sobre a estrutura física da Escola foi feita visando às necessidades dos alunos surdos. Infelizmente, foi constatado que todos os espaços não possuem 
informação de identificação em Libras, algo que deveriam ter pensado, já que existem surdos usuários da Língua de Sinais na instituição.

Com esta pesquisa buscamos não apenas identificar possíveis problemas relacionados à aprendizagem do aluno surdo, mas também foi pensada como processo formativo para o professor da escola. Queríamos que houvesse a participação do corpo docente, de modo que percebesse as implicações na construção da educação inclusiva e o efetivo resultado de sua prática pedagógica. Assim, trabalhamos com uma abordagem metodológica qualitativa, baseada nos princípios da pesquisa colaborativa, sinônimo de articulação entre pesquisa e formação docente.

Na perspectiva da metodologia colaborativa, juntos, pesquisadores e professores, estudam, discutem e analisam as práticas pedagógicas. No caso específico desta pesquisa, tínhamos como objetivo verificar como era feito o planejamento, como acontecia a execução em sala de aula e se a produção e o uso dos materiais didáticos estavam de acordo com as necessidades do aluno surdo. Como declara Ibiapina (2008, p. 37), "[...] a pesquisa colaborativa envolve a seleção de ações de pesquisa voltadas para a formação contínua de professores".

Extremamente desafiadora, a colaboração como princípio de pesquisa possibilita parceria com troca de saberes e possibilidades de transformação de práticas pedagógicas.

A prática de pesquisa colaborativa envolve investigadores e professores tanto em processos de produção de conhecimentos quanto de desenvolvimento interativo da própria pesquisa, haja vista que $\mathrm{o}$ trabalho colaborativo faz com que professores $\mathrm{e}$ pesquisadores produzam saberes, compartilhando estratégias que promovem desenvolvimento profissional (IBIAPINA, 2008, p. 25).

Mais do que pesquisar sobre o professor, pesquisamos com o professor, pois no trabalho colaborativo o exercício de reflexão é basilar. $\mathrm{Na}$ perspectiva de uma reflexão crítica, procuramos contribuir para que a professora colaboradora identificasse quais as teorias ou princípios teóricos que embasavam as suas ações e compreendesse a relevância das suas intenções como protagonista do processo de ensino-aprendizagem. 
Adotamos como procedimentos metodológicos para a construção de dados entrevistas individuais, sessões reflexivas e videoformação. A condução do trabalho pautou-se em quatro passos de pesquisa: descrição das práticas docentes, informação e interpretação do descrito, confronto entre teoria e prática e, por fim, reconstrução das práticas docentes (IBIAPINA, 2008).

Em todas essas etapas nosso papel foi crucial para incentivar a professora colaboradora a refletir e observar o contexto da sua prática em sala de aula de modo inclusivo, com o objetivo de alcançar todos os alunos, inclusive os surdos. Essas ações prepararam o caminho para que a professora colaboradora confrontasse a própria prática. Ela foi estimulada a responder perguntas que a levaram a repensar e a propor mudanças no que considerava importante do ponto de vista pedagógico, havendo a possibilidade de reconstrução de sua prática para melhor lidar com seu alunado.

\section{RESULTADOS E/OU DISCUSSÕES}

\section{a) Planejamento para turma de ouvintes com a presença de aluno surdo}

Como o docente de História planeja suas aulas, tendo em vista atender às particularidades do aluno surdo, sempre fez parte de nossas preocupações. Acreditávamos que o domínio sobre os princípios do ato de planejar para o ensino contribuísse para que o professor não deixasse de pensar nas especificidades desse alunado. Dessa forma, em um trabalho colaborativo, iniciamos os preparativos para a realização de duas sessões reflexivas sobre o tema "Planejamento de aula de História". O trabalho pautou-se em Azevedo (2013) e foi orientado pelos quatro passos de pesquisa sugeridos por Ibiapina (2008), já citados anteriormente.

Planejar aulas de História significa organizar um trabalho docente com o propósito de formar um cidadão social capaz de refletir sobre diferentes experiências humanas em diferentes tempos e espaços. Para que isso se efetive é premente que o docente tenha claras as suas definições teóricometodológicas. 
A Constituição Federal de 1988 (BRASIL, 1988) e a Lei de Diretrizes e Bases da Educação Nacional, Lei 9.394/96 (BRASIL, 1996), atestam o pleno desenvolvimento da pessoa por meio da garantia de seu direito à educação. Sob essa ótica, o princípio da igualdade de condições para o acesso e permanência na escola impõe um trabalho diferenciado para que o aluno surdo, por exemplo, tenha condições de atingir os mesmos objetivos pedagógicos que o aluno ouvinte.

Na busca por uma educação de qualidade para a comunidade surda, o grande avanço veio com a Lei 10.436/02 (BRASIL, 2002), que reconhece a Libras como língua da comunidade surda, e o Decreto Federal 5.626/05 (BRASIL, 2005), que estabelece as diretrizes que norteiam a educação dos surdos no ensino regular. Asseguram, também, que os surdos devem ter acesso a toda a escolarização através de sua língua natural; que as instituições federais de ensino devem promover cursos de formação de professores para o ensino e uso da Libras, tradução e interpretação de Libras-Língua Portuguesa, e para o ensino da Língua Portuguesa como segunda língua; e que as escolas devem contar com profissionais formados nesses cursos para que realmente se efetive o desenvolvimento de uma educação voltada também para esse alunado. Conforme o Decreto, os professores devem se apropriar de métodos diferenciados e flexíveis, para permitir que o público surdo alcansse os objetivos de uma escolarização com qualidade.

De certo, planejar para situações de ensino-aprendizagem não é tarefa simples, pois requer do docente um trabalho constante de pensar e repensar ações envolvendo muitos e variados sujeitos. No trabalho com a professora colaboradora, inicialmente, foi preciso fazer aproximações entre a temática da sessão reflexiva e as suas considerações sobre o ato de planejar. Foram muitos os questionamentos no intuito de fazê-la descrever a sua prática de planejar aulas, como por exemplo: O que você entende por planejamento de aula? Como você planeja suas aulas, considerando as particularidades de alunos surdos? Você já leu sobre o processo de ensinoaprendizagem com alunos surdos em turmas regulares? Como você 
descreve as suas aulas de História em termos teóricos e metodológicos? Como você descreve as suas ações em sala de aula direcionadas à aprendizagem de alunos surdos?

Inicialmente, assim se pronunciou a professora colaboradora:

Pra mim, o planejamento é a base do trabalho, é a base do seu trabalho, você tem que... Mesmo você não colocando no papel, você situa, todo o professor, por mais que ele saiba, tem que pegar o conteúdo ali e dar uma estudada, dar uma lida, procurar alguma coisa, e se ele não fizer isso... Como é que ele vai se estruturar? Mesmo que não vai num papel escrito e tudo, mas dá uma lida e olha... vou fazer assim, assim, assim. Não está escrito, mas você planejou $\left(7^{a}\right.$ Sessão reflexiva - Tema: Planejamento [2a sobre o tema], 05/06/2017).

De fato, colocar no papel não é uma condição do exercício do planejamento, sobretudo para professores com muitos anos de experiência docente. Domínio de conteúdos disciplinares e metodologia de ensino são condições já estabelecidas pelo docente, sem dúvida. A prática do detalhamento do ato de planejar caberia melhor para o professor iniciante, cujos pressupostos metodológicos poderiam estar, ainda, em construção. Contudo, a revisão do trabalho a que a professora faz referência aponta para os saberes disciplinares. Destaca a importância de o docente rever o conteúdo, estudá-lo antes para melhor estruturar a aula. Sentimos a falta de saberes e conhecimentos próprios do ensino, que, de certo, a obrigariam a pensar sobre os alunos, suas especificidades e processos de aprendizagem.

Azevedo (2013) atribui que o documento escrito é uma base orientadora das ações do professor, mas, também um instrumento que possibilita que $O$ profissional possa realizar constantes revisões e aprimoramento da sua prática ao longo dos anos. A autora afirma ainda que: "[...] Em todas as profissões o aprimoramento profissional depende da acumulação de experiências, a construção contínua e avaliada contribui para isso. Sem um planejamento sistemático e documentado pode-se criar limites para a avaliação cuidadosa do processo" (AZEVEDO, 2013, p. 11).

Sobre a sistematização do planejamento, vale destacar que a coordenação pedagógica da Escola solicita que os professores o façam. 
Para tanto, a colaboradora produz algo, mas sem especificidades teóricas ou metodológicas:

[...] é, a gente faz tipo uma ementa, coloca o objetivo geral, os específicos e lista de conteúdo, aí colocamos os procedimentos e recursos e avaliação. E às vezes a gente nem coloca. Pedem para a gente colocar só a ementa e a listagem de conteúdos. Mas geralmente a gente coloca os recursos, o que vai ser utilizado, os materiais. ( $1^{a}$ Sessão reflexiva - Tema: Planejamento [ $1^{a}$ sobre o tema], 15/05/2016).

Não há, portanto, tratamento de especificidades formativas, as quais seriam evidenciadas em um planejamento mais detalhado, como defende Azevedo (2013). Mas como as particularidades do conhecimento histórico poderiam chegar ao público surdo? O que de específico poderia ter em um planejamento de aula de História nesse cenário? Concordamos com Azevedo (2013, p. 6), quando afirma que "[...] contribui para o bom funcionamento das atividades previstas no planejamento e o consequente êxito deste, a realização de um diagnóstico (com descrição e interpretação) sobre o público escolar para o qual o plano foi elaborado [...]".

Ao percebermos as ideias da professora colaboradora sobre o ato de planejar, era preciso entender, de forma mais específica, como tais ideias se configuravam de acordo com as particularidades da História. Dessa maneira, questionamos: Há elementos que são comuns no planejamento de aula, seja qual for a matéria ou disciplina, mas, em uma aula de História, o que, especificamente, não poderia faltar no planejamento do professor?

\footnotetext{
A discussão. Para iniciar o assunto eu tenho que fazer alguma coisa, tem que esclarecer alguma coisa. Às vezes nem esclarecer, mas inicio - assunto e tenho que colocar algo da atualidade, se tiver acontecendo, infelizmente nesse tempo de Brasil hoje em dia tem muita coisa. $\left(7^{a}\right.$ Sessão reflexiva - Tema: Planejamento $\left[2^{a}\right.$ sobre 0 tema], 05/06/2017).
}

A professora faz menção ao que chamamos de contextualização. Retomamos: Mas o que teria de específico de uma aula de História? A colaboradora não deixa claro. Evidenciamos a necessidade de que saberes pedagógicos e da experiência sejam integrados ao universo do trabalho docente. Do contrário, trabalha-se com base, apenas, ou sobretudo, nos 
saberes disciplinares ou curriculares, nos moldes definidos por Tardif (2000), não atingindo de forma adequada as necessidades de todos os alunos da turma.

A sala de aula e a escola são espaços atualizados por novos desafios a cada ano. O trabalho com aluno surdo em turma regular é um exemplo disso. Para que o trabalho do docente, que não tem uma qualificação no domínio de Libras, atinja tal aluno, é preciso um planejamento que ao menos o aproxime do que está sendo trabalhado em sala de aula. Ao trabalhar nessa perspectiva, o professor contribuirá para o aperfeiçoamento constante da própria prática. Pensando desta maneira, foi que sentimos a necessidade de, mais uma vez, questionar a professora colaboradora: Como você faz o seu planejamento de aula e como leva em consideração as particularidades de alunos surdos em sala? Poderia descrever isso?

\footnotetext{
É, o ano passado eu levava em conta isso, porque tinha um aluno que tinha problemas. No caso ele é total. Aí quando você chegou e quando Magda que é professora de Libras também chegou, as duas chegaram no mesmo ano. Aí eu fui procurando e fui modificando a questão de planejamento. ( $7^{a}$ Sessão reflexiva - Tema: Planejamento [2 $2^{a}$ sobre o tema], 05/06/2017).
}

A colaboradora não consegue ver o surdo apenas como alguém que se comunica através de outra língua. "Alguém que tem problema" é algo de outra dimensão, ela não compreende que se trata apenas de uma diferença de língua. Para sabermos como de fato se deu essa modificação no planejamento, questionamos: Foi modificando o planejamento de que forma? Ao insistir no questionamento, a colaboradora esclarece: "Aí veio a questão do mapa conceitual, eu estou usando o mapa conceitual. No caso, pra todos, independente de ser surdo, que ajuda né? Mas pra todos". (7a Sessão reflexiva - Tema: Planejamento [2a sobre o tema], 05/06/2017).

Pelas respostas da professora colaboradora, não há atenção às particularidades do surdo. Isso faz com que improvisações ocorram em sua prática. Ou, em uma situação pior, faz com que o surdo seja, na aula dela, invisibilizado. Quantos mais serão ignorados pelas escolas? Para evitar improvisação em sala de aula é preciso planejar. Conforme Azevedo (2013), 
- planejamento previne descuidos docentes, dá mais segurança e qualidade ao trabalho do professor. Aquele que planeja e pensa sobre tal ato, reflete sobre ele e, assim, autoqualifica-se.

A sala de aula pode ser também um espaço formador para 0 professor. A formação inicial não pode dar conta da variedade e da complexidade de situações com as quais o futuro professor se defrontará. Nem ele estaria maduro para assimilar todos os desafios que a prática pedagógica coloca. A sala de aula e a escola podem favorecer o aperfeiçoamento profissional do professor, na medida em que ele considere as práticas que aí acontecem como objeto de análise, tendo em vista a proposição de alternativas que qualifiquem o ensino e melhorem a aprendizagem (GARRIDO, 2012, p. 125-126).

Verificamos dificuldades de explicação sobre escolhas metodológicas, bem como de articulação entre teoria e prática no exercício docente da colaboradora. Em ocasião anterior (entrevista, setembro/2016), ela declarou sobre o tipo de metodologia utilizada em suas aulas: "Faço aulas expositivas". Utiliza o Datashow para expor os conteúdos e complementa com vídeos relacionados aos temas propostos. Ela acredita que os vídeos com imagens alcançam melhor o alunado surdo. Ao fazer menção aos referenciais teóricos, assim se posicionou ao ser questionada sobre a utilização de algum referencial sobre o ensinar História:

De como ensinar História não, não, não. Assim, eu já procurei, mas também ninguém nunca falou, eu acho se tem alguma coisa assim "como ensinar História". Porque, assim, a gente tem a prática na universidade, a prática não! A teoria, mas a prática mesmo você só vai adquirir dentro de sala de aula. Você não sai da universidade, pelo menos eu não saí da universidade sabendo o que ia enfrentar fora dela. Eu não sei se algum colega (risos), aconteceu isso com algum colega, mas comigo é assim. E os colegas que depois eu encontrei disseram exatamente isso, não tem. É totalmente diferente, totalmente mesmo (CONCEIÇÃO, $2^{a}$ entrevista, 09/09/2016).

Supomos existir relativa frequência desse problema entre os formados em História no período de conclusão do curso da colaboradora (1987 a 1990), pois discussões e, sobretudo, mudanças nas concepções e práticas voltadas para a formação de professores de História ocorreram de forma mais forte só a partir da década de 1990. Mesmo assim, como afirma Oliva (2000-2001, p. 128), nos anos seguintes persistiu "um eco do tradicional esquema $3+1$, quando a formação específica era dada nos três primeiros 
anos, seguida de mais um ano de formação pedagógica". Nesta formação, as disciplinas, em grande medida, distanciadas das chamadas "disciplinas de conteúdo" da área (História), contavam ainda com a inexpressiva experiência de docência em sala de aula na forma de prática de ensino. Dessa forma é que a articulação entre teoria e prática, tão defendida entre profissionais da Educação, parece não se consolidar na prática da professora colaboradora.

Em uma sessão formativa de cunho colaborativo, é preciso levar os docentes partícipes, colaboradores, a um processo de confronto com as suas próprias impressões. Por isto, foram feitas perguntas que exigiam da colaboradora voltar às suas experiências, a fim de discorrer sobre elas, levando-se em consideração o estudo dos textos das sessões e os diálogos com os pesquisadores. Partindo dos resultados de sessões reflexivas anteriores, insistimos na experiência do confronto dos estudos da professora colaboradora com a própria prática, para fazê-la reconhecer a necessidade de sempre buscar mais informações, com o objetivo de contemplar, também, o aluno surdo. Se não fosse a oportunidade de participar de uma pesquisa colaborativa, talvez a professora não viesse a pensar sobre isso e permanecesse considerando, apenas, a responsabilidade de outros, a exemplo do intérprete.

Em função do trabalho colaborativo, a professora colaboradora chegou, ao final dessa reflexão, a reconhecer que a presença do intérprete em sala de aula não seria suficiente para resolver o distanciamento dos alunos surdos dos conteúdos ministrados. Como professora, ela precisaria fazer algo para mediar as relações com esse público.

No processo de aprimoramento profissional, tem peso importante a reflexão sobre a prática. Ela possibilita que o professor revise, defina e aprimore suas escolhas teóricas e metodológicas. Dessa forma, concordamos com Azevedo (2010, p.11), quando afirma que:

A reflexão do professor passa efetivamente pela questão da busca contínua pela melhoria na qualificação profissional, mas também pelos princípios adotados pelo professor, que, como educador, 
precisa ter claramente definidos seus objetivos e concepções de História, bem como sua postura teórico-metodológica, além de sensibilidade frente às questões da escola e dos alunos.

Tendo em vista todos esses aspectos, na ausência de relações entre teoria e prática, e na busca por aprofundar a compreensão sobre a experiência sensível da colaboradora frente às questões do aluno surdo, indagamos de outra forma: Como você descreve as suas ações em sala de aula direcionadas à aprendizagem de alunos surdos?

No ano passado, no caso com o menino, eu trabalhava mais com slides, aí depois eu percebi com os estudos [da pesquisa colaborativa] e com as orientações da outra menina, que não adiantava muito não só os textos e as imagens. Aí eu comecei a trabalhar de outra forma, colocando algumas imagens e pouquíssimos textos, falando e olhando para ele para fazer a leitura labial, e a avaliação com ele eu fazia a normal, ele fazia e tirava nota melhor que os outros, quer dizer, não melhor, mais igual aos outros, os ditos normais. (7 ${ }^{a}$ Sessão reflexiva Tema: Planejamento [2a sobre o tema], 05/06/2017).

Percebemos ações de reconstrução do próprio trabalho relacionadas com os estudos e a pesquisa colaborativa. Mas registramos que falar olhando para o surdo é algo necessário. Porém, já foi comprovado que o surdo, mesmo sendo excelente em leitura labial, não consegue entender de forma clara o que está sendo dito. Ronice Quadros (2002) menciona, ao citar Mary Duffy, que pesquisas nos Estados Unidos constataram que, mesmo com anos de vida, uma criança surda somente é capaz de captar, através da leitura labial, cerca de $20 \%$ da mensagem. Portanto, um dos mitos mais tenazes entre leigos na educação de surdos é o de que todo aluno surdo faz leitura labial: "[...] no contexto de aula expositiva, mesmo aqueles que foram bem treinados perdem entre $30 \%$ e $40 \%$ do que for dito", segundo Reily (2004, p. 127). Ou seja, nem todo surdo faz leitura labial. É preciso anos de treinamento para chegar a um nível razoável que na verdade gira em torno de, no máximo, $60 \%$ de entendimento.

Em ocasião anterior, ao questionarmos sobre a educação dos surdos e suas atividades docentes em relação ao assunto, a professora informou que não havia feito curso ou leitura sobre a Educação de Surdos, nem sobre a Língua de Sinais, e nem mesmo sobre a sua cultura. O que se fazia em sala 
de aula era trocar a realização de leituras de textos por slides, com os temas e figuras relacionadas para explicar os textos.

Diante desses aspectos, consideramos necessária a realização de sessão reflexiva como base de um processo formativo sobre o ensino para alunos surdos. A sessão foi realizada no mesmo mês da entrevista inicial.

Ao afirmar, na sessão reflexiva sobre planejamento, a necessidade de "Melhorar a prática dirigida pra ele, além da prática normal de sala de aula pra ele também se sentir inserido nesse contexto" (7 $7^{a}$ Sessão. Tema: planejamento [ $2^{a}$ sobre o tema], 05/06/2017), a professora colaboradora demonstra que percebe a necessidade de, ao buscar atender às particularidades da turma, cuidar em planejar melhor a prática direcionada ao aluno surdo. Não é mais o intérprete que tem que estar em sala de aula apenas. Como professora de História da turma, precisa planejar melhor de modo geral e de forma específica para os alunos surdos. A análise das sessões reflexivas indicava que a colaboração parecia atingir a professora, e com o propósito de ouvi-la a respeito, assim questionamos:

Pesquisadora: Em sua opinião, as sessões reflexivas que realizamos até - momento caracterizaram-se como pesquisa colaborativa e contribuíram para a sua formação como docente?

Colaboradora: Com certeza colaborou, contribuiv e contribui.

Pesquisadora: De acordo com o que ouviu e leu de lbiapina, essas reflexões realmente se caracterizam como pesquisa colaborativa?

Colaboradora: Caracterizam.

Pesquisadora: E contribuíram para sua formação como docente?

Colaboradora: Pra formação e pra melhoria, pra melhoria. ( $7^{a}$ Sessão. Tema: planejamento [2a sobre o tema], 05/06/2017).

A professora colaboradora sabia bem o significado da pesquisa colaborativa, como observamos em sua afirmação:

É que a pesquisa colaborativa, ela, como eu já falei, ela leva à reflexão, essa reflexão leva também a uma mudança de atitude, e já que vai ter uma reflexão então eu vou perceber como é que o trabalho está sendo feito, se tem alguma, algo que possa acrescentar, num é? E se tem o que eu vou acrescentar, como eu vou acrescentar pra ver se ele atinge pelo menos o objetivo que é a aprendizagem $\left(2^{a}\right.$ Sessão reflexiva - Tema: Pesquisa colaborativa, 16/09/2016). 
Ao orientar as sessões reflexivas pelos textos selecionados, bem como pelas fases do processo reflexivo (IBIAPINA, 2008), chegamos ao momento de problematizar o processo avaliativo de sala de aula. Assim ocorreu o diálogo:

Pesquisadora: De que maneira você verifica, constata, supõe e avalia se os seus alunos aprenderam aquilo que era esperado nas aulas, isso de modo geral e, particularmente, sobre os alunos surdos?

Colaboradora: Pronto, o que ela coloca aqui (texto) é exatamente isso. Da questão dela ser formativa, dela ser global, contínua, principalmente contínua, diversificada, integradora, apaziguadora, explícita, é exatamente isso aqui.

Pesquisadora: Então você já trabalhava dessa forma?

Colaboradora: Exatamente. É comum para mim, no meu entender. Não sei dos colegas... É desse jeito, não tem como ser diferente não.

Pesquisadora: Então é por isso que não houve uma mudança, pois você já estava adequada a isso?

Colaboradora: É exatamente isso, sem tirar nem por, nem colocar uma vírgula nem ponto. É exatamente assim, exatamente assim que funciona ( $7^{a}$ Sessão. Tema: planejamento $\left(2^{a}\right.$ sobre 0 tema), 05/06/2017).

A professora, mais uma vez, mesmo sendo questionada de forma explícita sobre o aluno surdo, não o considera. Avalia seus alunos de modo amplo, considerando aspectos formativos, globais, de forma contínua e diversificada. Que aspectos formais e amplos integravam a avaliação da aprendizagem do aluno surdo? O que a avaliação contínua e à luz de variados procedimentos tem demonstrado sobre a aprendizagem desse aluno? Exemplos de questões que seguiam sem resposta.

No decorrer das sessões reflexivas sobre planejamento, foi possível perceber que a professora colaboradora interpretou o que leu, apropriou-se do assunto e o relacionou com a sua prática docente, a ponto de explicitar que precisaria melhorar sua prática, especialmente no que se referia ao trabalho com aluno surdo. Mas isso não era suficiente, sobretudo pelos sinais de permanência de limites, a exemplo dos procedimentos de avaliação. $O$ sujeito precisa confrontar-se com suas percepções, práticas e representações para ter condições de vivenciar um processo de reconstrução. Nesse sentido, na busca por uma síntese formativa, foi preciso questioná-la: "Conceição, como um professor de História deve planejar suas aulas de modo a atingir de fato a aprendizagem dos alunos?" 
Eu utilizaria o modelo de Azevedo do planejamento, principalmente por causa da questão norteadora, porque a partir desta questão ele vai se estimular, quando lança a questão ele vai pensar e a partir daí você vai colocando as suas estratégias, no caso, desenvolvendo a metodologia ( $7^{a}$ Sessão. Tema: planejamento $\left[2^{a}\right.$ sobre o tema], 05/06/2017).

Sentimos a falta do aluno surdo e, igualmente, $o$ peso que as estratégias têm nas percepções da professora. Como explorar os conhecimentos do aluno surdo por meio de questões norteadoras? Nada a respeito! E "colocar as estratégias" como sinal de "desenvolvimento da metodologia" não pode se sustentar. Metodologia está para além de um conjunto de estratégias de aula (recursos e técnicas). O que se destaca positivamente é o fato de a professora colaboradora insistir em organizar suas aulas e trabalhar em sala a partir da orientação de Azevedo (2013, p. 14), sobre planejamento de aula de História. Isto significa que os estudos e conversas sobre planejamento, nas sessões reflexivas, levou a colaboradora a pensar na aula por inteiro, como uma unidade orgânica, algo que não se improvisa quando se pretende qualidade.

E o aluno surdo, onde ficava no imaginário docente? Era preciso instigar mais uma vez sobre isso. Assim, questionamos a colaboradora: Em uma turma regular com a presença de alunos surdos, se você fosse ou tivesse que repensar ou refazer algo em suas aulas, com o intuito de melhor atingir tais alunos, o que e como você faria, reformularia, modificaria?

Pra atingir os ouvintes e os alunos surdos tem que mudar a estratégia. A gente sabe que ele não está ouvindo, tem que colocar algumas figuras, alguns sinais (Libras) pra ele perceber o que é que eu quero dizer, e como eu quero atingir ele, e como ele vai aprender, qual vai ser o resultado da aprendizagem dele. ( $7^{a}$ Sessão. Tema: planejamento [2a sobre o tema], 05/06/2017).

Mais uma vez o peso das estratégias de aula aparece como imagens a serem utilizadas e sinais. No intuito de aprofundar o raciocínio da colaboradora, foi preciso insistir:

Pesquisadora: Tem mais alguma coisa que você reformularia?

Colaboradora: $O$ essencial mesmo era a presença da intérprete.

Pesquisadora: Da intérprete de Libras? 
Colaboradora: Exatamente. A minha parte é limitada, eu teria que buscar pra no caso aprender a linguagem de sinais pra atingi-lo. Pra eu conseguir passar para ele.

Pesquisadora: Então, não é só a metodologia por trás disso, tem uma língua. Se não tiver essa língua não vai adiantar esse planejamento, essa metodologia?

Colaboradora: Não vai adiantar, a não ser que ele saiba a questão da leitura labial, mas, mesmo assim, acho que ainda fica dúvidas.

Pesquisadora: Então, pra você, o que modificaria é o que você já tem falado e a questão do intérprete?

Colaboradora: Do intérprete, da presença do intérprete. O planejamento é importante, a metodologia, o processo avaliativo, mas se não tiver a presença da intérprete vai ser difícil, impossível não, mas vai ser difícil (7 $7^{a}$ Sessão. Tema: planejamento [2a sobre o tema], 05/06/2017).

A professora colaboradora destaca que, ao perceber que um aluno não está entendendo, por "estar em outro mundo", por exemplo, o professor precisa se questionar sobre "o que (...) fazer para ele acordar, para ele chegar". Isso é relevante em se tratando de surdos em sala de aula. O que fazer para que eles estejam, de fato, na aula aprendendo história? Infelizmente, a fala da professora não deu indicativos de resposta. Com receio de insistir mais e gerarmos algum desconforto à colaboradora, tendo em vista que já estávamos na segunda sessão reflexiva sobre a temática "planejamento de aula de História", nada mais questionamos a respeito. Indicativos de reconstrução de práticas apareciam, mas também sinais de limites, permanências.

\section{b) A prática docente e a produção de material didático}

Integrar-se a projetos colaborativos requer a crença de que mudanças são possíveis, quando se tem o objetivo de resolver problemas que perpassam o cotidiano dos que fazem e vivem a escola. Com este propósito, organizamos parte do trabalho colaborativo com a atenção voltada para o fazer pedagógico baseado na construção e uso de recursos didáticos. Considerando a importância da leitura visual pelos surdos, tornava-se necessário refletir sobre os recursos trabalhados pela professora. Assim, a produção de conhecimentos sobre Educação ocorreria ao mesmo tempo em que seriam possibilitadas melhorias no desenvolvimento profissional da colaboradora. 
Verificamos, por meio de entrevista, que a professora colaboradora, formada em História, possuía 24 anos de docência na área; entretanto, apesar da experiência em sala de aula, não possuía conhecimentos sobre as especificidades dos alunos surdos. Questionamos: "Você fez algum curso de Libras ou algum estudo relacionado? Fez alguma leitura sobre a educação de surdos ou a cultura deles?" Assim, pronunciou-se:

Colaboradora: Não, nunca fiz, nunca fiz nenhum curso não.

Pesquisadora: Procurou ler, tentou ver alguma coisa?

Colaboradora: Não, não procurei não, a única coisa que eu faço, [...], passei a fazer, foi a preparação da aula com slides [...] para não ficar na leitura, porque leitura ele não vai ouvir, e eu colocando os slides então ele vê as figuras e o texto, lê o texto, então eu tento amenizar isso. Já vi vídeo também com legenda, um vídeo que eu tenho [...]. Em casa eu consigo ver com legenda, mas eu não consigo gravar. Aqui eu já pedi à menina que toma conta aqui, mas ela não consegue gravar aqui com legenda, não aparece. Aí seria maravilhoso se tivesse, né? (CONCEIÇÃO, $2^{a}$ entrevista, 09/09/2016).

A professora colaboradora não participou de cursos disponibilizados, nem houve iniciativa para buscar leituras relacionadas que pudessem ajudála a entender sobre as necessidades do aluno surdo. Percebemos o desafio e, ao mesmo tempo, a oportunidade de, por meio da pesquisa colaborativa, mudar essa realidade. Para a professora, ministrar as aulas com slides foi um avanço, mas, na prática, esse recurso não faz muita diferença para surdos. Destacou também o uso de figuras e vídeos com legendas; entretanto, para que realmente haja aprendizado é necessário pensarmos que as imagens precisam ser trabalhadas na própria língua do público escolar, e que vídeos com legenda, que muitos consideram a solução, não resolvem, visto que os surdos fariam a leitura na língua portuguesa.

Será que um surdo domina uma língua que não é visual? Além de não ser tão fácil dominar uma segunda língua, a Libras, reconhecida pelo Decreto 5.626/05 como a língua natural da comunidade surda, possui uma estrutura bem diferente da língua portuguesa. Na Libras, não se encontra conjugação verbal, gênero e determinados pronomes próprios do português. Diante disso, afirmamos que a legenda não é o ideal para os surdos e, quando usada, necessita de adaptações. Assim, fica evidente a 
lacuna de conhecimento em relação às especificidades do aluno surdo, abordadas em uma sessão reflexiva.

Buscando saber o que a professora conhecia sobre o aluno surdo presente em sua sala de aula de turma regular, perguntamos: "Você poderia falar um pouco em relação a ter esse aluno surdo em sala de aula? Fale também um pouco sobre ele, se você está tendo problemas e como estão sendo abordados os conteúdos".

A dificuldade dele. Eu tenho 2 alunos, 2 alunos que tem problema de audição [...] é difícil saber a dificuldade dele exatamente, porque não chegam para tirar dúvidas não, tem um que eu acho que não sabe ler. [...]. Já chegou com essa deficiência na leitura e o outro não, o outro já é mais... ele faz leitura labial, mas eu acho que ainda tem dificuldades, e a minha experiência em relação a outros alunos com esse mesmo problema: não tenho nenhuma. Eu, eu do tempo que trabalho, nunca tive alunos com problemas de audição, não é? No caso deles, eu creio que é total, nunca tive, é a primeira vez que eu estou tendo esse, alunos desse jeito, né? Com problemas na audição (CONCEIÇÃO, $2^{a}$ entrevista, 09/09/2016).

Percebemos que a colaboradora não tem segurança da real necessidade de um dos alunos, quando declara: "acho que não sabe ler". Seria isto possível, alguém estar no Ensino Médio e não saber ler? Em outro momento, a professora diz: "é difícil saber a dificuldade dele exatamente, porque não chegam para tirar dúvidas", evidenciando que além de não haver aproximação, ela espera a procura do aluno. Vimos que não há uma interação. Como ele fará isso se utiliza outra língua para se comunicar e a professora não domina a Libras?

Fica evidente que a professora colaboradora compreende a surdez como um "problema". Um equívoco da parte dela, visto que a surdez não é sinônimo de comprometimento cognitivo, trata-se apenas de uma condição na qual as pessoas compreendem o mundo de modo diferente, pelo canal visual, e se comunicam por meio de outra língua. Salientamos mais uma vez que nem todos os surdos fazem leitura labial e que ela é um meio insuficiente para a comunicação. Outro aspecto que vale destacar é a passividade da professora, evidenciada quando afirma "nunca tive, é a primeira vez que tenho" alunos surdos. A entrevista foi feita no segundo semestre letivo de 
2016. Por que a professora ainda não tinha buscado estratégias diferenciadas ou procurado conhecer as características específicas desses alunos?

Ao perguntar se a colaboradora olhava o caderno dos alunos ou se usavam o livro, respondeu que via o de Pedro, porém o de João, não. Cruz, Aspilicueta e Leite (2009) mencionam a importância do vínculo afetivo entre professor e aluno na ampliação do interesse do aluno para o aprender. $O$ que havia? Desinteresse em saber mais sobre seus dois alunos surdos ou o desconhecimento das especificidades desse alunado?

Sobre a língua especificamente, o ensino de História para surdos deve considerar as particularidades das duas línguas (Libras e Língua Portuguesa), cada uma de natureza comunicacional diferente, mas que precisam ser trabalhadas de maneira intercaladas e inter-relacionadas, uma no auxílio da outra (PEREIRA, 2017). Esse aspecto não integra a prática da professora, a qual organiza suas aulas, aparentemente, pela divisão dos capítulos do livro. Isso fez com que houvesse outro questionamento: Você usa só livro? Usa outros recursos para dar aula?

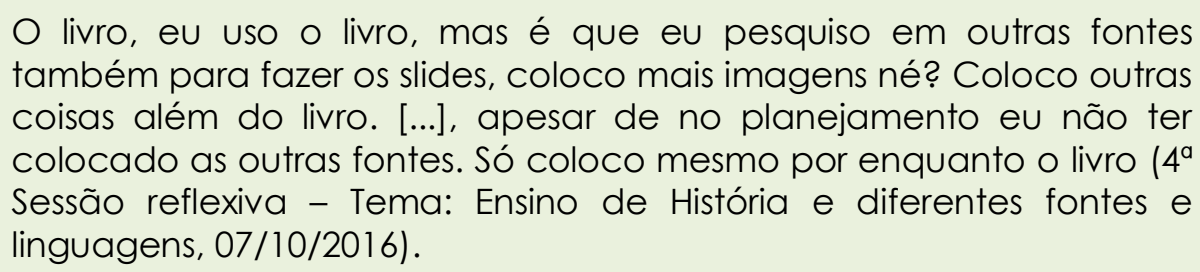

Quanto ao uso de imagens, Neves (2009) relata sobre a importância do seu uso em atividades, de forma concomitante, com perguntas em português escrito, relacionadas a um determinado período histórico estudado. As respostas podem ser apresentadas, primeiro, em Língua de Sinais, para depois serem transcritas para o português escrito. Outro aspecto importante é a utilização de muitas imagens na aula, em vez da exploração exaustiva de uma ou duas imagens, prática comum utilizada com alunos ouvintes.

Sem conhecimento acerca da educação de surdos e da Libras, decidimos, em conjunto, por uma sessão reflexiva voltada para estratégias 
metodológicas para o ensino de alunos surdos. Assim, trabalhamos a partir do texto de Lacerda, Santos e Caetano (2013), selecionado, também, de forma conjunta. As definições metodológicas do professor são, em grande medida, condição para a aprendizagem dos alunos. O texto escolhido, de forma direta e contundente, apontava estratégias para o ensino de alunos surdos. Além disso, realizamos sessão reflexiva acerca do uso de diferentes fontes e linguagens em sala de aula de História. Nessa sessão, especificamente, questionada sobre a criação de materiais pedagógicos, assim declarou:

É, eu uso os slides e uso também vídeos, vídeos de curta duração, no tempo que durante a aula dá para assistir, geralmente de 10 minutos, no máximo 20 minutos, [...] faço como fechamento ou então como uma introdução, coloco o vídeo, eles assistem, aí depois vem a questão dos comentários, discussões (4a Sessão reflexiva Tema: Ensino de História e diferentes fontes e linguagens, 7/10/2016).

As perguntas exploradas até este ponto permitiram identificar que eram necessárias melhorias na prática pedagógica da professora colaboradora, a fim de atender aos alunos surdos. Sobre o uso de vídeos mencionado pela docente, por exemplo, é preciso considerarmos o que declaram Azevedo e Lima (2011, p.74): "É preciso domínio a respeito das novas linguagens e fontes levadas à sala de aula, para que o ensino de História não assista à dissolução das suas especificidades".

Em termos de avaliação, os recursos diáticos utilizados também apresentam limites. O aluno João, por exemplo, não apresenta trabalhos, não faz exercícios, os mesmos indicados para os ouvintes. Então, o que ele faz nas aulas de História da EEBW? Adianta um surdo estar inserido em uma escola regular se não avança na aquisição do conhecimento e desenvolvimento de habilidades? A EEBW possui uma excelente estrutura, porém precisa que sua equipe tenha atenção em relação a esse alunado. É lamentável que uma escola não esteja preparada para garantir uma educação de qualidade para os alunos surdos. A professora diz que Pedro acompanha melhor os conteúdos por ser oralizado, porém na avaliação 
escrita não alcança a média. São os exercícios e a apresentação dos trabalhos que the permitem atingir a nota necessária.

Além de ser aplicado o mesmo recurso de avaliação, também são os mesmos critérios de correção das provas de surdos e ouvintes; isto seria aceitável caso o surdo acompanhasse os conteúdos curriculares e tivesse acesso a eles como os demais.

O Decreto 5.626/05 orienta que as avaliações sejam acessíveis, com linguagem clara e "mecanismos de avaliação coerentes com 0 aprendizado de segunda língua, na correção das provas escritas, valorizando o aspecto semântico". Não se trata de fazer uma avaliação fácil, mas com adaptações necessárias, levando em conta que o surdo tem a língua portuguesa como segunda língua (L2) e que imagens contextualizadas tornam o texto mais claro.

Antes da sessão reflexiva sobre metodologia para o ensino de alunos surdos, a colaboradora não tinha um olhar direcionado para as necessidades desse público. Ela tem claro o objetivo da sessão reflexiva, que é estudar o texto para trazer novidades para a sua prática pedagógica. Percebemos na fala da professora abertura para uma possível mudança, quando disse que o texto dá nortes e caminhos para melhorar a prática. Destacamos o entendimento dela de que todo movimento em busca de melhorar a prática, consequentemente sua metodologia para o ensino do surdo, também beneficiará os demais alunos: "favorece também aos outros, os ouvintes". Na continuidade do comentário da professora é evidente que o texto proporcionou reflexões, como se mostra a seguir.

Outra questão importante também é a questão do aluno surdo, como diz aqui no texto: "deste modo é frequente que este aluno chegue ao espaço escolar com conhecimentos de mundo reduzido, quando comparados com os apresentados pelos alunos que ouvem". Dá a entender, dá a entender não. A gente entende, né? Que ele vem com o conhecimento reduzido. Mas, uma reflexão que eu faço neste ponto [...]. Para gente, ele vem com esse conhecimento reduzido, mas será que ele... Na verdade eu acho que ele vem com um conhecimento diferente. Acho até que a gente não podia dizer reduzido. Eu acho. Porque... o que eles são? $O$ que é que eu sei que eles são? Não é isso? Talvez seja mais reduzido para mim. Não é? Porque ele tem o conhecimento de mundo dele, 
que é diferente do meu ( $3^{a}$ Sessão reflexiva - Tema: Metodologia para o ensino de alunos surdos, 23/09/2016).

A colaboradora comenta sobre o estigma que é frequente, e que Lacerda, Santos e Caetano (2013) também mencionam que o aluno surdo chega ao espaço escolar com conhecimento reduzido, e argumenta: "Eu acho que ele vem com um conhecimento diferente, ou seja, não podemos dizer que é reduzido, o surdo compreende o mundo através da visão, diferente da maioria, não significa que seu conhecimento seja propriamente reduzido, e sim diferente". Percebemos a relevância da sessão reflexiva, que evidencia um conhecimento que antes não estava presente em falas da professora. As reflexões, a partir do estudo e discussão sobre o texto, fizeram com que ela desenvolvesse um olhar diferente para o alunado e buscasse uma forma de proporcionar acesso de qualidade aos conteúdos curriculares.

Em outro momento da investigação, fizemos a sessão de videoformação, que consiste em filmar uma aula da professora colaboradora, com o objetivo de que ela se veja em ação e possa refletir sobre suas práticas em sala de aula, pensando em possibilidades de mudança. Durante a sessão, questionamos:

Pesquisadora: Você acha que está tudo bom? Tem alguma coisa que você percebeu e não percebia em relação à sua aula?

Colaboradora: Hum. Não, mas a questão assim do slide poderia ser bem melhor (risos)

Pesquisadora: Por que os slides poderiam ser melhores?

Colaboradora: Para facilitar a questão de compreensão mesmo.

Pesquisadora: Você acha que facilitaria para toda turma?

Colaboradora: Para toda a turma com certeza facilitaria. Acho que faltou mais figuras, não é? Faltou mais figuras nesse primeiro momento, porque tinha os textos, tinha umas figuras, mas acho que foram poucas $\left(6^{a}\right.$ Sessão reflexiva - Tema: videoformação, 18/11/2016).

Mesmo assistindo ao vídeo, a professora colaboradora não foi além da identificação de necessidade de mudanças nos slides, as quais seriam limitadas à inserção de mais figuras correspondentes aos textos escritos. Instigamos a sua reflexão por meio de questionamentos, a fim de possibilitarmos um processo de reconstrução de práticas. Como suas 
reflexões não avançaram, problematizamos o fato de, em certo momento da aula, ela ficar de costas para a turma, impedindo o aluno surdo até mesmo de tentar ler seus lábios. O intuito era fazer com que a colaboradora pensasse na sua aula como um todo integrado e com comunicação efetiva e permanente.

Com o interesse sinalizado pela professora de estudar mapa conceitual como recurso didático, apresentamos obras sobre o tema. Em decisão conjunta, realizamos sessão reflexiva a partir da obra de Moreira (1997), a qual contribuiu para que a professora colaboradora amadurecesse o exercício de produção de mapas conceituais, a fim de atingir a todos da sala de aula.

Praticamente durante todo o primeiro semestre, o aluno João, citado anteriormente pela professora com a fala "acho que não sabe ler", não frequentou a Escola. O aluno chegou ao Ensino Médio sem sabe ler e, até mesmo o propósito da socialização estava comprometido pelas suas ausências. Segundo a professora colaboradora, apesar de o ano letivo já estar avançado em seu segundo semestre, não houve nenhuma ação da EEBW, no sentido de verificar o motivo das faltas do aluno.

Na sessão reflexiva sobre metodologia para o ensino de alunos surdos, questionamos a colaboradora sobre a contribuição dada à sua formação, a qual respondeu:

Na parte pedagógica, eu pensei que a Libras ia resolver todos os meus problemas, o intérprete no caso, mas percebo que não. Não é só a questão de existir o intérprete que vai resolver todos os problemas do surdo. É necessário existir também toda uma estratégia da minha parte para ele atingir $\left(3^{a}\right.$ Sessão reflexiva - Tema: Metodologia para o ensino de alunos surdos, 23/09/2016).

Muitos profissionais se enganam achando que apenas a Libras na sala de aula resolve toda a questão de ensino-aprendizagem do aluno surdo. Porém, o professor precisa pensar no material que será usado e qual a metodologia adequada para esse alunado. Há também uma tendência de o professor querer passar toda a responsabilidade ao intérprete de Libras, como se ele tivesse a qualificação adequada para o ensino; vale a pena 
lembrar que a função do intérprete é distinta da do professor. Ao questionarmos a professora sobre o que ela queria dizer em "atingir", sua resposta foi "a compreensão, o entendimento"; ela comenta que precisa melhorar a comunicação, e para tanto precisa aprender a Libras. A fala da professora, na sequência, resume como o texto a impactou, fez refletir e abriu caminho para a mudança de sua prática.

Eu sei que eu preciso. Eu preciso aprender algo sobre a Língua de Sinais. Eu preciso fazer leituras, preciso fazer leituras. Ninguém vai me ensinar. Eu é que tenho que buscar. Vai me ensinar se eu for buscar. Então eu necessito fazer todo esse trabalho e melhorar também a prática ( $3^{a}$ Sessão reflexiva - Tema: Metodologia para o ensino de alunos surdos, 23/09/2016).

Seguindo as orientações da colaboração como princípio de pesquisa, que apontam para a necessidade da reconstrução das práticas docentes, e ao pensar no desenvolvimento do aluno surdo e na ação da professora colaboradora, sentimos a necessidade de questionar: "O que poderia acontecer para que realmente João e Pedro também pudessem ter melhor acesso ao conteúdo?".

É, eu acho que teria que ter a intérprete. Era essencial a existência da intérprete dentro de sala de aula (...) para falar. Então você tá falando, tá expondo conteúdo e eles estarem acompanhando, então isso aí dificulta muito, essa questão que eles não têm intérprete (CONCEIÇÃO, $2^{a}$ entrevista, 09/09/2016).

Realmente é necessária a presença de um intérprete em sala de aula. De acordo com a legislação em vigor, é o meio para garantir o direito de o aluno surdo ter acesso aos conteúdos curriculares através da língua brasileira de sinais. Até o momento em que foi realizada a pesquisa, a Escola se encontrava sem intérprete de Libras, ou seja, um semestre inteiro sem o apoio desse profissional. Este fato pode ser um dos fatores para justificar a ausência do aluno na Escola.

O ideal para o trabalho com alunos surdos está previsto no Decreto 5.626/05: cada Escola deve contar com uma equipe composta por professores de português como segunda língua, professores de Libras e intérpretes. Em conjunto, essa equipe, deve dar suporte ao professor da 
disciplina no planejamento das aulas quanto à escolha adequada de materiais e atividades para o aluno surdo.

A professora colaboradora percebeu que o mundo do surdo é visual e que apesar de trabalhar com slides pensando nesse aspecto as adaptações são necessárias. Em relação à produção de slides, houve modificações no material trabalhado com a turma durante o período da pesquisa. Se anteriormente ela usava apenas produções com textos escritos, passou, depois da pesquisa, a acrescentar imagens relacionadas aos textos, ainda que com necessidades de avanço em prol de melhorias. Cada imagem poderia estar em slides diferentes, com os seus textos correspondentes, e espaçamento de 1,5 entre linhas. É permitido, em alguns casos, para melhor compreensão e contextualização, mais de uma imagem, observando para que não haja uma poluição visual; ou seja, tornar-se mais parecido com uma obra artística ao invés de ter a finalidade de levar o aluno a uma aprendizagem significativa e não a uma admiração artística de cores e traços.

Assim, em relação ao material pedagógico visual (slides), podemos afirmar que houve avanços na forma em que foram elaborados pela professora colaboradora. Em parceria com o professor de Libras, que pertence ao quadro de profissionais da EEBW, poderá atingir uma maior qualidade no planejamento e elaboração desse material para alcançar as necessidades do alunado surdo.

\section{Considerações finais}

Apesar de perceber, nas sessões reflexivas, que os respectivos textos base da professora colaboradora apresentavam-se marcados com caneta marca-texto, o que era um sinal de leitura, havia dúvidas quanto à efetividade dos estudos, visto que algumas perguntas pareciam não ser bem compreendidas, mesmo tendo sido construídas com muito cuidado. Inclusive, em algumas delas, foram levados em consideração palavras dos 
próprios textos, com o intuito de que fossem claras, não gerando margem para interpretações diferenciadas.

Ao que parece, a professora colaboradora pensou sobre a sua prática e percebeu como melhorá-la. Entretanto, questionávamos em silêncio: Como ocorreriam melhorias no processo de proximidade com os alunos surdos? Como contextualizaria a aula para esses alunos? Como os avaliaria, levando-se em consideração suas particularidades? Já sentíamos a necessidade de continuidade da pesquisa para verificar, em sala de aula, tais possibilidades de mudança na prática da professora.

Diante da constatação de dificuldades de leitura e escrita em língua portuguesa, pelos alunos surdos, no Ensino Médio, ressaltamos a necessidade de se evitar a postura simplista de defender que as aulas podem ser baseadas no uso de imagens e com a presença de um intérprete, já que o surdo se comunica e aprende principalmente pelo canal visual. Os defensores dessa postura esquecem que os surdos vivem inseridos em uma sociedade ouvinte que utiliza a língua portuguesa. O próprio Decreto Federal 5.626/05 afirma: "A Língua Brasileira de Sinais - Libras não poderá substituir a modalidade escrita da língua portuguesa". Portanto, faz-se necessária uma visão integral das necessidades educacionais do aluno surdo que fundamente a prática do docente, sendo iniciada com um planejamento mais global e inclusivo.

A prática da metodologia de pesquisa colaborativa foi adotada com esse intuito, o de melhorar o planejamento e as práticas pedagógicas do professor de História com o aluno surdo. A professora percebeu que estava muito distante das especificidades do aluno surdo, assim como da produção e uso mais adequado de materiais didáticos. Expressou sua disposição de mudar algumas práticas e ainda comentou que isso não iria se refletir como melhoria apenas para o alunado surdo, mas que beneficiaria também aos alunos ouvintes.

Esse aspecto da reflexão docente sobre sua própria prática demonstra que a professora colaboradora começou a ter outro olhar em relação ao aluno surdo. Isto ficou ainda mais evidenciado quando a professora 
colaboradora mencionou, na sessão reflexiva sobre metodologia para o ensino de alunos surdos, que o surdo não tem um "conhecimento reduzido e sim um conhecimento de mundo diferente". A pesquisa colaborativa contribuiu para a conscientização da professora sobre as necessidades específicas do aluno surdo e motivou mudanças atitudinais que se refletiram na sua prática pedagógica e, por consequência, na sua produção de recursos didáticos.

Ainda existe um longo caminho para implementar, em todas as Escolas com surdos, a equipe de profissionais prevista no Decreto Federal 5.626/05, cujas práticas vão além do Atendimento Educacional Especializado - AEE. Com a pesquisa colaborativa, por ora, concluímos com a certeza de ter contribuído para mudanças na prática pedagógica da professora colaboradora, com a esperança de que este trabalho possa inspirar melhorias de ensino para os surdos também em outros espaços escolares.

\section{Referências}

AZEVEDO, C. B. de; LIMA, A. C. da S. Leitura e compreensão do mundo na Educação Básica: o ensino de História e a utilização de diferentes linguagens em sala de aula. Roteiro. v. 36, n. 1, p.55-80, jan/jun-2011.

AZEVEDO, C. B. de. A renovação dos conteúdos e métodos da História ensinada. Revista Percursos. v. 11, n. 2, p. 7-27, Dossiê: Ensino de História, Florianópolis, UDESC/FACED, Jul.-Dez. 2010.

AZEVEDO, C. B. de. Planejamento docente na aula de história: princípios e procedimentos teórico-metodológicos. In: Revista Metáfora Educacional. $\mathrm{n}$. 14, jan-jun/2013. p. 3-28.

BRASIL. Constituição da República Federativa do Brasil. Brasília: Imprensa Oficial, 1988.

BRASIL. Lei de Diretrizes e Bases da Educação Nacional. LDB 9.394, de 20 de dezembro de 1996.

BRASIL. Lei №. 10.436, de 24 de abril de 2002. Dispõe sobre a Língua Brasileira de Sinais - LIBRAS e dá outras providências. 
BRASIL. Decreto No 5.626, de 22 de dezembro de 2005. Regulamenta a Lei № 10.436, de 24 de abril de 2002.

CRUZ, G. de C.; ASPILICUETA, P.; LEITE, C. D. Escolarização de pessoas surdas na escola regular: explorando aspectos da comunicação na inclusão escolar. Práxis Educativa, v. 4, n² 2, p.169-176, jul-dez, 2009.

CUNHA, C., Professora. $2^{a}$ entrevista [Setembro de 2016]. Natal, 09 de setembro de 2016. Câmera filmadora. Segunda entrevista concedida à pesquisa sobre prática pedagógica do professor de História em turma regular com a presença de aluno surdo.

GARRIDO, E. Sala de aula: espaço de construção do conhecimento para o aluno e de pesquisa e desenvolvimento profissional para o professor. In:

CASTRO, A. D. de.; CARVALHO, A. M. P. de. (Org.). Ensinar a ensinar: didática para a escola fundamental e média. São Paulo: Cengage Learning, 2012, p. $125-141$.

IBIAPINA, I. M. L. de M. Pesquisa colaborativa: investigação, formação e produção de conhecimentos. Brasília: Líber Livro Editora, 2008.

LACERDA, C. B. F. de; SANTOS, L. F. dos; CAETANO, J. F. Estratégias

metodológicas para o ensino de alunos surdos. In: LACERDA, C. B. F. de; SANTOS, L. F. dos (Org.). Tenho um aluno surdo, e agora? Introdução à Libras e educação de surdos. São Carlos: EdUFSCr, 2013. p. 185-200.

MESQUITA, V.; SILVA, A. C. A exclusão do incluído: a busca pelo equilíbrio. Revista Fazendo História. Ano II, edição III, 2009.

MOREIRA, M. A. Mapas conceituais e aprendizagem significativa. Instituto de Física da UFRGS, 1997. p. 87-95. Disponível em: <http://www.if.ufgs.br/public/tapf/v24_n6_moreira_.pdf>. Acesso em: 10/11/ 2016.

NEVES, G. V. Ensino de História para alunos surdos de Ensino Médio: desafios e possibilidades. In: IX Congresso Nacional de Educação EDUCERE. Anais. 26 a 29 de outubro de 2009. PUC-PR.

OLIVA, T. A. de. Ensino de História, conhecimento histórico e formação de professores. Revista Brasileira de Educação. n. 6/7, p. 119-130, Dez.Jan. 20002001.

PEREIRA, C. C. A. F. Ensino de História para surdos: práticas educacionais em escola pública de educação bilíngue. Educação Básica Revista, v. 3, n.1, 2017. 
QUADROS, R. M. de. O tradutor e intérprete de língua brasileira de sinais e língua portuguesa. Secretaria de Educação Especial. Programa Nacional de Apoio à Educação de Surdos. Brasília: MEC/SEESP, 2002.

REILY, L. Escola inclusiva: Linguagem e mediação. São Paulo: Papirus, 2004.

TARDIF, M. Saberes profissionais dos professores e conhecimentos universitários: elementos para uma epistemologia da prática profissional dos professores e suas consequências em relação à formação para o magistério. Revista Brasileira de Educação. n.13, jan/fev/mar/abr. 2000, p.5-24.

YOKOYAMA, L. Reflexões sobre o ensino de História para alunos surdos. ANPUH - XXIII Simpósio Nacional de História. Anais. Londrina, 2005. Sessões reflexivas citadas:

$1^{a}$ Sessão reflexiva - Tema: Planejamento. Realização em 15 de maio de 2016. Filmagem feita na sede da Escola (EEBW).

$2^{a}$ Sessão reflexiva - Tema: Pesquisa colaborativa. Realização em 16 de setembro de 2016. Filmagem feita na sede da EEBW.

$3^{a}$ Sessão reflexiva - Tema: Metodologia para o ensino de alunos surdos. Realização em 23 de setembro de 2016. Filmagem feita na sede da EEBW.

$4^{a}$ Sessão reflexiva - Tema: Ensino de História e diferentes fontes e linguagens. Realização em 07 de outubro de 2016. Filmagem feita na sede da EEBW.

$6^{a}$ Sessão reflexiva - Tema: videoformação. Realização em 18 de novembro de 2016. Filmagem feita na sede da EEBW.

$7^{a}$ Sessão reflexiva - Tema: Planejamento [ $2^{a}$ sobre o tema]. Realização em 06 de junho de 2017. Filmagem feita na sede da EEBM.

Recebido em: 01 de fevereiro de 2020

Aprovado em: 22 de junho de 2020

Publicado em: 02 de setembro de 2020 